\title{
WORKPLACE DEVIANCE REVIEW - A PHILOSOPHICAL STANCE
} Mamoona Arshad $^{1 *}$, Muhammad Abdur Rahman Malik ${ }^{2}$

${ }^{1 *}$ Ph.D., Candidate, Suleman Dawood School of Business, Lahore University of Management Sciences (LUMS), Pakistan; ${ }^{2}$ Associate professor, Suleman Dawood School of Business, Lahore University of Management Sciences

(LUMS), Pakistan.

Email: ${ }^{1 *}$ mamoona.arshad19@gmail.com, ${ }^{2}$ abdur.malik@lums.edu.pk

Article History: Received on $1^{\text {st }}$ June 2021, Revised on $18^{\text {th }}$ July 2021, Published on $25^{\text {th }}$ July 2021

\section{Abstract}

Purpose of the study: The research aimed to compile extensive literature on workplace deviance typology.

Methodology: The research comprises a systematic literature review. The review helps to understand the extensive work on workplace deviance (1983-2019). The articles were shortlisted based on PRISMA, preferred reporting items for systematic reviews, to provide a clear picture. Based on 75 shortlisted articles from financial times (FT) - 50. The shortlisted articles comprise four clusters, i.e., antecedents, consequences, mediators, and moderators.

Main Findings: The research found the need to explore future research based on a social constructivist lens.

Applications of this study: The research provides a way forward to extend research in workplace deviance. Research developed a framework to guide future research on the new relationships of workplace deviance. Hence, empirical work on these relationships can offer new insights into construct dimensionality, methodology, and philosophy.

Novelty/Originality of this study: After highlighting the key contributions of the previous researchers, the research attempted to articulate the ontology of workplace deviance by suggesting the need to investigate it through a different philosophical lens. Researchers then identified various gaps to be addressed in the future.

Keywords: Workplace Deviance, Interpersonal Deviance, Organizational Deviance, Systematic Literature Review, Social Constructivist Perspective.

\section{INTRODUCTION}

Workplace deviance (WD) can be defined as a "voluntary behaviour that violates significant organizational norms and in so doing threatens the well-being of an organization, its members, or both" (Robinson \& Bennett, 1995, p. 556) With the turn of a century and the emergence of WD typology by Robinson and Bennett (1995), the interest in the constructs increases (Mackey et al., 2019). To provide a comprehensive picture of the WD research, the present research aims to articulate the ontology of WD typology.

Researchers have primarily emphasized the sources and outcomes of the WD. The mutual theme of these researchers has remained on studying the rule-breaking, norm violation, the elements and reasons behind individual norm-deviating behaviours (Malik \& Lenka, 2018). The studies that intend to conceptualize the concept of 'deviance' as behavioural acts inconsistent with societal groups have been defined under the functionalist approach (Dennis \& Martin, 2005). Alternatively, Bryant and Higgins (2010) pointed out the importance of an interactionist lens for exploring deviance in organizations. They viewed the role of social interactions as imperative for individuals, as these interactions provide meanings and facilitate them to interpret these interactions. The Individuals perceive these interactions differently and interpret them in their way. Therefore, Bryant and Higgins (2010) highlighted that interactionist perspective as relevant in expanding the theory of WD. Despite the significance of investigating the 'social construction of bad behaviours' within the organization (Arshad \& Malik, 2020), the lack of attention regarding what makes WD socially constructed (Bennett \& Robinson, 2003) persists. The research is divided into the following sections. Firstly, it provides an overview of the concept of WD and its definitional concern. Secondly, the methodology to analyse the literature is presented, followed by the discussion on four emergent clusters. Finally, the research delineates the future direction, limitation, and conclusion.

\section{LITERATURE REVIEW}

\section{Definition}

The concept of deviant behaviours has been associated with behavioural aspects of individuals, perceived as undesirable organizational behaviours in the past. Examples of such behaviours are absenteeism, theft, harassment, physical aggression, or sabotage (Robinson, 2008, p. 143). The definition later included the harmful behaviours, ranging from minor to severe behaviours, intent to harm either the individual or organization. The definition excludes behaviours such as wearing a casual dress at work, etc. (Robinson \& Bennett, 1995), i.e. the behaviours which do not mean to harm anyone.

Two distinct and widely discussed manifestations of WD in literature are production deviance and employee theft, such as property deviance (Hollinger, 1986). Many scholars have attempted to classify the deviance at the workplace (Hollinger \& Clark, 1982; Mangione \& Quinn, 1975). These attempts have served as a foundation for developing an 
integrative deviant behaviours typology for Robinson \& Bennett (1995). They developed the typology by classifying these behaviours along two dimensions and into four categories. A) Property deviance- "Occasions where employees tend to acquire or damage the tangible assets of their workplace without approval" (Hollinger \& Clark, 1982, p. 333). B) Production deviance - "behaviours that violate the formally prohibited norms delineating the minimal quality and quantity of work to be accomplished" (Hollinger \& Clark, 1982, p. 333). C) Political deviance- "behaviour places other individuals at private or political hindrance as a result of social interaction". D) Personal aggression- behaviour where individuals show aggression towards other individuals (Robinson \& Bennett, 1995). The first two types are related to an organization, while the latter refers to an interpersonal form of deviance.

Later, Galperin (2003, p. 156) attempts to define the concept based on previous definitions suggesting that WD as the behaviours:

- WD can be conceptualized as intentional or purposeful behaviour, excluding voluntary or accidental action.

- These behaviours comprise acts that are intentionally harmful to the organization or individuals. It excludes the outsiders such as suppliers and customers.

The consensus has yet to be made, but the core idea is to harm the organization, other peers, or both. The widely used and operationalized definition of WD is "voluntary behaviour that violates significant organizational norms and in so doing threatens the well-being of an organization, its members, or both" (Robinson \& Bennett, 1995). Therefore, the two dimensions, i.e. organizational deviance (OD) and interpersonal deviance (ID) reflect the overall construct. 'OD' reflects behaviours that intend to harm an organization's interest, i.e. extending over time, shrinking working hours, stealing from an organization, or lying about hours worked. 'ID' reflects behaviours that intend to harm other individuals at work. These behaviours include verbal abuse, sexual harassment, blaming or gossiping about co-workers, etc. (Mitchell \& Ambrose, 2007).

\section{Operationalization of construct}

Numerous behaviours such as sabotage, absenteeism, theft, frustration, aggression have been used in literature to refer to WD. These behaviours, when combined for operationalizing WD, caused the concern of low variances, skewed distribution (Hanisch \& Hulin, 1991) on the one hand, and correlational issues among attitude and behaviour (Fishbein \& Ajzen, 1977) on the other. Considering these issues, Bennet and Robinson (2003) evolved the concept from mere depiction of individual behaviour to the broad conceptualization involving the behaviours committed by the organizational members.

Several constructs have been operationalized in the research to measure the concept of 'WD'. For instance, the WD has been operationalized in the literature by scholars such as; Stewart et al.'s (2009), Mitchell and Ambrose's (2007), Spector et al.'s (2006), Fox and Spector's (1999), and Aquino et al. (1999). Marcus and colleagues (2016) highlighted that despite the availability of several scales, most studies used Bennett and Robinson's (2000) scale. Therefore, suggesting census on using Bennett and Robinson (2000) for operationalizing their construct.

The research aims to answer the following research questions:

$\mathrm{RQ}_{1}$ : Which antecedents, mediators, moderators, and consequences determine workplace deviance?

$\mathrm{RQ}_{2}$ : Which philosophical lens can extend workplace deviance research in the future?

\section{METHODOLOGY}

The systematic review allows commenting on the ontology of WD. Given its transparency to enhance the worth of the review process, a systematic review is frequently adopted by business and management research scholars $\underline{\text { Bouncken et }}$ al., 2015).

The literature for the present study was identified using electronic databases and search engines, including Scopus. The field of WD is extensive and comprises a vast range of data sources. To deal with reliability and validity issues, the research used Scopus as a search engine (Mongeon \& Adèle Paul-Hus, 2016). The search terms used were deviance, deviant behaviours, workplace deviance, organizational deviance, and interpersonal deviance. These terms were explicitly used to cater to the development of Robinson and Bennett's typology. A total of 542 articles were found after putting inverted commas. (e.g. "deviant behaviour") which was reduced to 445 after the removal of duplicates. Articles further reduced to 400 after restricting the search for 'journal articles' specifically deals with deviant behaviours in organizational/work contexts (see Figure 1).

\section{Selection of articles}

The search results were from Scopus exported through bibliographic management software Endnote to Microsoft Excel. Microsoft Excel was used to save data under numerous headers, including author name, document title, year, source title, and abstract. The researchers used Scopus to search related studies to avoid any potential elimination of the research articles (Podsakoff et al., 2012). To consolidate the research on WD and ensure reliability in the results, articles were shortlisted from Financial Times (FT) 50 journals (related to management, HR, and organizational behaviour). From 
these top 15 management and OB-related journals, 144 related articles were shortlisted based on eligibility (Table 1). Exclusion of non-related articles (e.g. constructive deviance, based on contrary definition, book reviews, or theoretical) further reduced the related articles to 75, ranging from 1983 to 2019.

\section{RESULTS}

The literature has primarily evidenced the studies from the functionalist approach (Bryant \& Higgins, 2010). A functionalist approach builds upon the interrelationship of society, which accounts for societal influence (Mooney et al., 2007). This approach highlights the societal aspects impacting the social world, WD scholars have widely used this approach. It shows an influence from the large social groups and institutions.
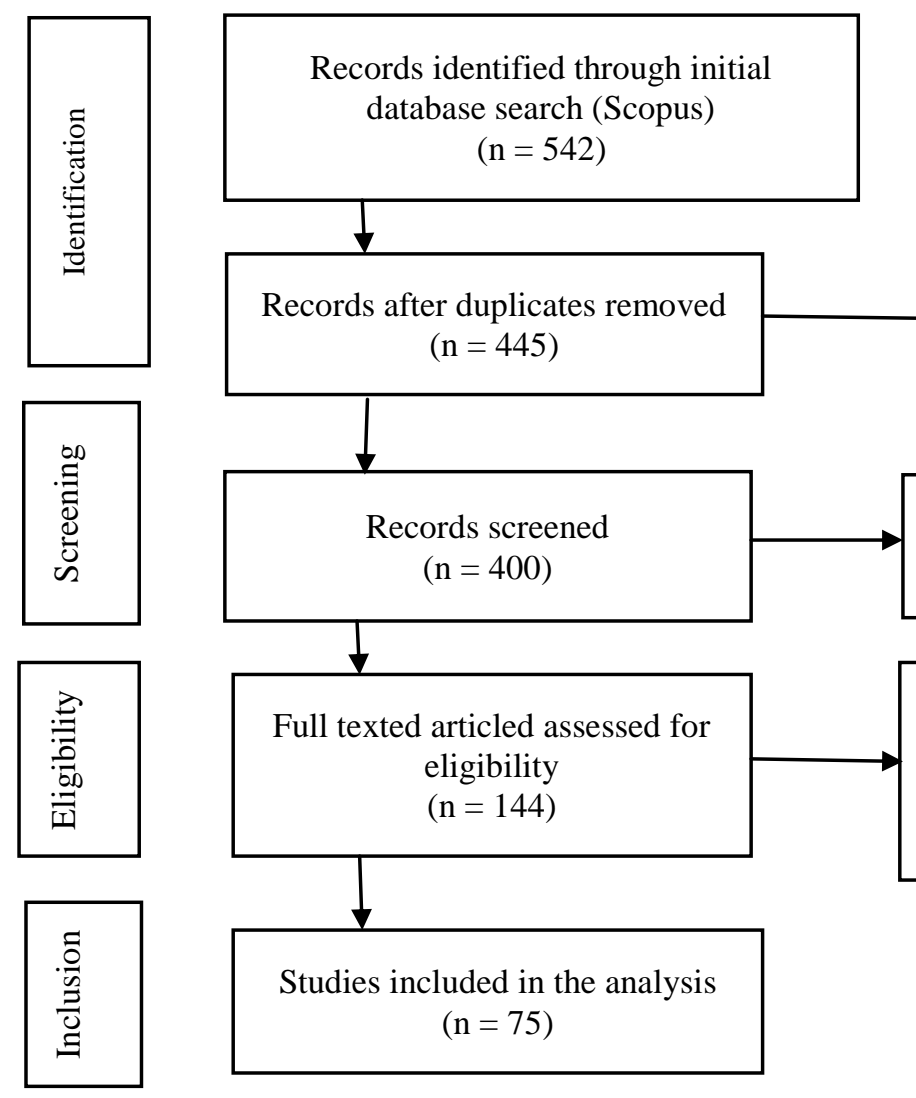

Removed (45 conference papers, meeting notes, and book chapters)

Excluding all journals other than FT50 journals

69 articles without antecedent, consequences of workplace deviance, or unrelated to research question

Figure 1: Flow diagram of literature screening

Table 1: List of shortlisted journals (1983-2019)

\begin{tabular}{llccc}
\hline From FT-50 journal list & Short title & Total Articles & Shortlisted \\
\hline 1. & Academy of Management Journal & AMJ & 7 & 6 \\
\hline 2. & Academy of Management Review & AMR & 8 & 2 \\
\hline 3. & Administrative Science Quarterly & ASQ & 4 & 2 \\
\hline 4. & Human Relations & HR & 18 & 7 \\
\hline 5. & Human Resource Management & HRM & 5 & 2 \\
\hline 6. & Journal of Applied Psychology & JAP & 26 & 18 \\
\hline 7. & Journal of Business Ethics & JBE & 38 & 18 \\
\hline 8. & Journal of Management & JOM & 19 & 9 \\
\hline 9. Journal of Management Studies & JMS & 3 & 0 \\
\hline 10. & Organization Science & OSci & 5 & 0 \\
\hline 11. & Organizational Behaviour and Human Decision Processes & OBHDP & 11 & 11 \\
\hline & & & $\mathbf{1 4 4}$ & $\mathbf{7 5}$ \\
\hline
\end{tabular}

\section{Overview of the workplace deviance research}

The literature consists of four clusters, namely antecedents, mediators, moderators, and consequences of WD. The research has further separated with the year 1995 as a reference point. The literature can be separated before and after 1995, as a significant chunk of the research on WD has been evident after this period. Except for one study, all other research appeared after 1995. Hence, the discussion comprises the studies conducted after 1995. The prime reason behind the upward trend in WD research after 1995 attributes to the seminal work of Robinson and Bennett (1995). They 
developed typology and measure $\underline{(2000)}$ of the construct (Figure 2). Each of the studies has contributed differently to the body of knowledge.

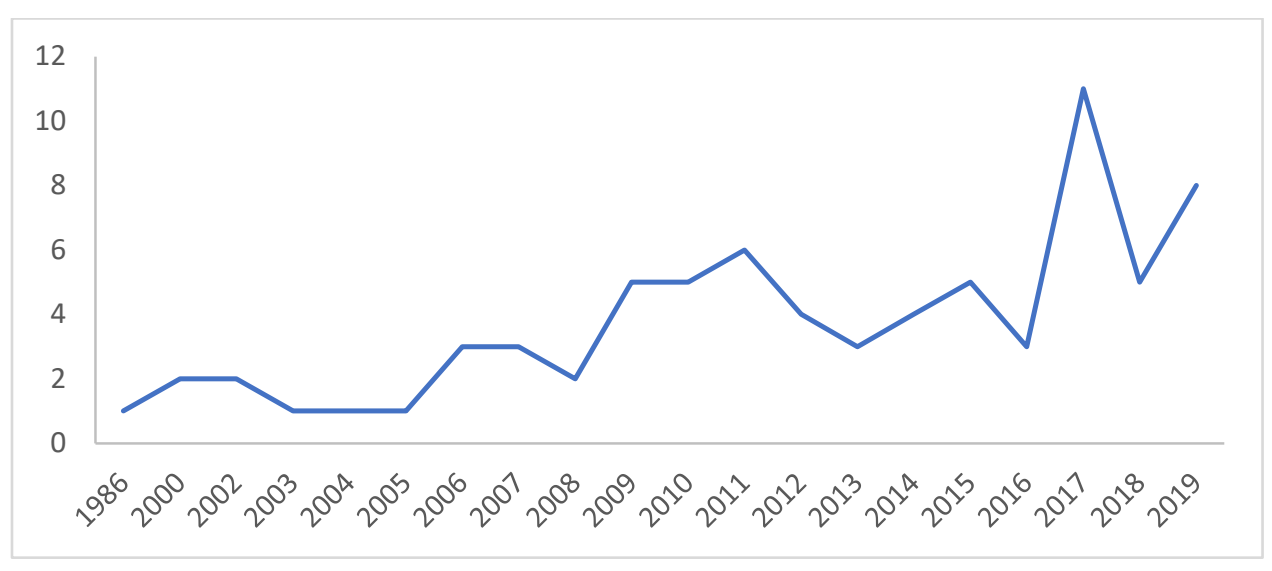

Figure 2: Trend in publication

Several studies adopted quantitative approaches, while only two studies used experiments and manipulation. Contrarily, qualitative analysis was scarce as only one of 45 studies conducted interviews. This evidence shows that a significant portion of research on WD typology has used survey instruments. The lack of qualitative studies is dominantly evident from the results. Furthermore, concerning the research designs, the literature opted for ' 360 -degree feedback' or crosssectional data (with data collected at one, two, or three-point in time). The survey participants were employees, managers, executives, students, and professionals from different industries, suggesting that most of the research in the area of WD has used either individuals or dyads as their unit of analysis.

Based on the systematic review, the research can divide the literature into 4 clusters. The following section discusses antecedents, consequences, mediators, and moderators of the literature to date.

\section{Antecedents of workplace deviance}

In cluster 1, the antecedents that determine individuals' tendency toward WD are analysed. (Figure 3).

The literature shows the dominance of the social exchange principle in directing employees' OD (Collins \& Mossholder, 2017; Huang et al., 2017). The superiority of the individuals at dominant positions significantly influences their representativeness in the organizations (Vogel \& Mitchell, 2017). For instance, when supervisors depict their dark traits or negative attributes, individuals perceive acceptance of negative traits and support for unethical conduct within the organization (Mayer et al., 2012; Ogunfowora et al., 2021). On the other hand, ethical leadership plays an important role in emanating a negative impact on the organization through involving employees in citizenship and ethical behaviour (Gok et al., 2017; Mayer et al., 2009; Mo \& Shi, 2017). Hence, it results in increasing affective commitment, individual trust, and psychological resources (Neves \& Champion, 2015), thereby lowering the likelihood of negativity in the form of WD.

Besides leadership traits, individual differences and their distinct personalities also determine deviant acts. For instance, an individual's core self-evaluation (Kluemper et al., 2019) and ability to manage emotions predict his capacity to perform and direct WD (Kluemper et al., 2011). Likewise, the interaction of an idealist and realist individual results in OD, not ID (Hastings \& Finegan, 2010). Additionally, Machiavellian employees also hold a likelihood of being deviant and destructive for the organization (Zagenczyk et al., 2014). Thus, a fit between an individual and his supervisor has been seen to be a way to reduce OD.

Individual perceptions also shape behaviour at work. Among various views, perception of justice and fairness lead to positive impact while the perception of injustice negatively impacts the individuals. The evidence shows that perceptions of justice values among employees reduce their chances of engaging in WD (Thornton \& Rupp, 2016). These perceptions, along with the job design e.g. autonomy, can be detrimental to the organization. Autonomy has contributed to OD in perceiving a threat to resources at work, resulting in job withdrawals (Wilson et al., 2015).

Stressors also predict employees' involvement in deviant acts. Stressful cues in the form of hindrance stressors can circumvent the adverse effects when employees invest resources in learning something new at work (Zhang et al., 2017) or when their external locus of control is low (Shoss et al., 2016). Conversely, stressors instigate WD among those having more employment opportunities or when LMX is lower (Ferris et al., 2009). Individuals can minimize the effects of stressors by building and securing resources for themselves (Hobfoll et al., 2018).

\section{Mediators of workplace deviance}

Cluster 2 describes variables that have emerged as a mediating mechanism between WD and other consequences (Figure 3). Dominant themes which emerged as a mediating role in literature are cognitive and affective states, emotions 
management, individual differences, self-regulation, and employee perceptions (e.g., justice, trust, perceived organizational support).

Individual personality differences discriminate their behaviour from positive to harmful at work. Variations in the level of self-esteem (Vogel \& Mitchell, 2017) and duty orientation (Hannah et al., 2011) impacts the degree of deviance at work. Where self-esteem in the presence of low psychological attachment attunes individuals to quit (Ferris et al. 2009), ethical leadership increases the duty orientation of employees over time hence less likely to provoke negativity (Hannah et al., 2011). Individual's moral emotions, such as the feeling of shame and anger, instigate them to justify their deviant behaviors (Harvey et al., 2017). However, the trust in leaders (Mo \& Shi, 2017), rewards expectancy (Shoaib \& Baruch, 2019), individual's guilt, and feeling of inauthenticity would not (Ebrahimi et al., 2020). Their inability to regulate emotions (Jahanzeb \& Fatima, 2018; Song et al., 2020), increased negative emotions (Zhang et al., 2017), disidentification (Fiset \& Bhave, 2021) engage employees in WD.

\section{Moderators of workplace deviance}

Cluster 3 provides the boundary conditions which influence the effects of antecedents on WD (Figure 3). The boundary conditions that either strengthen or weaken the intersection of WD with other constructs include cognitive and affective states, emotions management, individual differences, employee perceptions, and moral perspectives.

\begin{tabular}{|c|c|}
\hline $\begin{array}{l}\text { Cluster } 1 \text { - Antecedents } \\
\text { - } \quad \text { Leadership styles } \\
\text { - } \quad \text { Personality traits } \\
\text { - } \quad \text { perception of justice } \\
\text { - } \quad \text { P-O fit (e.g. Goal congruence). } \\
\text { - Work resources (i.e. autonomy) } \\
\text { - Stressors (role ambiguity, role conflict, } \\
\quad \text { hindrance stressors) }\end{array}$ & $\begin{array}{l}\text { Cluster } 2 \text { - Mediators } \\
\text { - Cognitive and affective states (psychological } \\
\text { contract, psychological entitlement, hostile } \\
\text { effective state, affective commitment, OCB, } \\
\text { employee engagement, trust, justice, social support } \\
\text { perceptions) } \\
\text { - Emotions management (anger, shame, guilt) } \\
\text { - Self-regulations (Self-control, state hostility, } \\
\text { - surface acting) } \\
\text { Dyadic relation (LMX), abusive supervision } \\
\text { Individual differences (self-esteem, duty } \\
\text { orientation, negative affect) } \\
\text { Rewards expectancy }\end{array}$ \\
\hline $\begin{array}{l}\text { Cluster 3-Moderators } \\
\text { - Cognitive and affective states (OCB, } \\
\text { employee engagement, emotional } \\
\text { intelligence) } \\
\text { - } \text { Emotions (Emotional exhaustion) } \\
\text { - Character perspective (moral identity, self- } \\
\text { evaluation, reputation for performance) } \\
\text { - Individual differences (self-esteem, LOC) } \\
\text { - Organizational constraints } \\
\text { - others (Competence uncertainty, job } \\
\text { embeddedness, intention to quit, } \\
\text { organization status, CSR, LMX, learning) }\end{array}$ & $\begin{array}{l}\text { Cluster } 4 \text { - Consequences } \\
\text { - } \quad \text { prevalence of deviance } \\
\text { - } \quad \text { subordinate deviance }\end{array}$ \\
\hline
\end{tabular}

Figure 3: Emergent clusters from literature

Individual and contextual elements significantly influence workplace deviance through the emotions of individuals (Harvey et al., 2017). Moral awareness influences the link between a leader's traits and WD involvement. Ethical leadership can compensate for individuals' lack of moral dispositions by providing them with an ethical model (Gok et al., 2017; Quade et al., 2019). Likewise, a higher external locus of control augments the perceptions of low power on production deviance (Shoss et al., 2016). Employees high in moral identity respond to the abusive supervisors through increased constructive resistance or quitting their jobs (Greenbaum et al., 2013). Their core self-evaluation (Shantz \& Booth, 2014), along with moral commitment (Greenbaum et al., 2013) and cognitive abilities (Kluemper et al., 2019), binds them to alleviate negativity through responding constructively to reduce harm. Additionally, the literature also shows that some individuals detach themselves from negative behaviours. This detachment is evidenced when employees perceive increased organizational justice (Shoaib \& Baruch, 2019), social self-efficacy (Fiset \& Bhave, 2021), and when no alternate jobs are available (Wilson et al., 2015) through managing their emotions. 
Finally, a low level of work engagement (Shantz et al., 2016) and organizational citizenship behaviour (Yam et al., 2017) also affect the link between antecedents and employees' increased involvement in deviant behaviours.

\section{Consequences of workplace deviance}

Cluster 4 addresses the outcomes of WD (Figure 3). Only a few studies have investigated the consequential side of WD (Eissa et al., 2020). One of the studies concerns the deviant organizational behaviours resulting from the normalization of deviance within the local community (Earle et al., 2010). As normalization is a complicated construct to measure, Earle and colleagues used a proxy of arrears to evidenced deviance in organizations resulted from the community at large. In a recent study, Mawritz et al. (2017) described the role of self-regulatory resources impairment as an intervening variable impacting subordinate deviance and abusive supervision. Abusive leadership is also an outcome of followers' inappropriate responses, such as deviation from norms. The review shows less research on the consequences of WD.

\section{FUTURE DIRECTIONS}

The literature on WD has emerged over the years to extend the theory. Division of the literature among four clusters has led us to identify the gaps in the field of WD. Therefore, the following section presents the research gaps in the literature to guide future research for both scholars and practitioners. The framework developed from future directions is in Figure 4.

\section{Multidimensional construct}

Robinson and Bennett's (1995) typology paves the way for developing a two-dimensional scale for WD (Bennett \& Robinson, 2000). These dimensions include OD and ID, consisting of seven items and nine items each respectively is a widely used instrument to date. Gruys (2003) assessed the multidimensionality of the construct through co-occurrence of data analysis and confirmed that deviant behaviours comprise two dimensions. Despite this, research on WD is primarily operationalized collectively to assess WD under the label of deviant behaviours, WD, or production deviance. Few studies have measured the construct as two-dimensional (Mackey et al., 2019). Hence, the research identifies that to make a distinction between ID and OD. This distinction will also facilitate exploring WD consequences. The metaanalysis provided evidence of the WD scale as two-dimensional (Berry et al., 2007). The meta-analysis recommends these two as viable for their two-dimensional operationalization. Therefore, it allows future researchers to explore the relationships of ID and OD through different antecedents. For instance, interpersonal level and organizational level constructs can be searched for and empirically analysed.

\section{Methodological advancements}

Rigour is portrayed as an essential element in 'evaluating the methodological rigor of existing survey-based research' (Malhotra \& Grover, 1998). Dominant research in WD relies on quantitative methods; therefore, future researchers must give high weight to rigour in quantitative survey-based studies. Unit of analysis has been initiated as one of the significant attributes in formulating a research question (Malhotra \& Grover, 1998). In this regard, the dominantly used unit of analysis in WD was individuals (60\% of studies), where some studies employed subordinate-supervisor dyads (22\% of studies). The remaining studies either used secondary data, interviews or developed a conceptual framework. These results suggest the need to analyse future studies from the organization and team/group as a unit of analysis. Future studies should focus on peer-rated or supervisor-rated responses to enhance the quality of responses. Using this will eliminate common method bias and self-desirability issues. Besides, most of the studies have used cross-sectional data, suggesting the need to conduct longitudinal studies. Longitudinal studies can guide the research in remarkable ways by developing policies and an understanding that either WD is a long-term personality trait or a situational state among individuals.

\section{Social constructivist perspective in the domain of workplace deviance}

Robinson and Bennett (1995) developed the typology by classifying the deviant behaviours into four categories i) Property deviance, production deviance, political deviance, and personal aggression. These categories state deviance as behaviour attempting to damage property acts in opposition to defined norms or behaves aggressively. All these provide evidence of WD as ontologically social and not actual. WD can also be specified as an ideal state due to its conception as an outcome emerging from a discourse. WD is an outcome of discourse; therefore, previously constructed evidence could mediate the link between WD and its consequences. For instance, when an individual observes that others are deviating from the work norms within the organization, the observation in itself makes the evidence real for the person in a sense that it can affect the behaviour of others as well. The previous argument suggests that the truths and meanings do not exist out there in the world; instead, they are outcomes of interaction among the subjects within the world (Chia, 2002). The subjects/individuals construct their meaning which varies even for the same phenomenon. These behaviours are the outcome of social interactions and human consciousness. The individual's perceptions ascertain their varying behaviours. This variation is due to organizational culture and prospects, such as relationships with peers or supervisors. Therefore, the research raises the need to consider WD that is not actual and comes under social constructivist epistemology. 
The research argues that the WD is a socially constructed phenomenon. Hence there is a need to scrutinize the concept from the structuralist and post-structuralist perspectives. Considering the nature of the concept as socially created rather than objective will provide a richer picture for its understanding (Bennett \& Robinson, 2003, p. 266). The prevalence of deviant behaviours in local community results in occurrences of such events at the organizational level has been empirically evident (Earle et al., 2010), providing a construct as 'socially constructive' in nature.

Keeping the importance of social construction in mind, the role of a context or culture is significant. These factors play a dominant role in understanding the overall structure separate from the organizational reality and ideas (Deleuze, 1953). The role of corporate culture and climate is also highlighting by several scholars (Aleksic et al., 2019; Narayanan \& Murphy, 2017; Salajeghe et al., 2016). Reality provides the edge for individuals to build a worldview that may shape their attitude and behaviours. Accordingly, organizational culture is a strong determinant of one's behaviour where the perception of an individual's and organizational norms specifies the individual's behaviour (Peng et al., 2016). Saussure (1959), a prominent figure of the linguistic turn, proposed that it is not the individuals who create language, instead, it's the sense that allows them to construct language. Therefore, the meanings given to each behaviour do not develop or build on certain norms instead are based on the culture of the organization. The perceptions of employees are grounded on these beliefs, which are formed from the social underpinnings and environment. This argument justifies that the context, i.e. culture and environment, are significant predictors and could create and program an individual's action. Therefore, the research suggests that functionalist and interactionist approaches are insufficient to analyse deviant behaviours. Further, the social constructivist perspective also plays its role in driving deviant behaviour within the organizations.

Future researchers should incorporate the less explored methods to investigate the phenomenon of deviant acts. The qualitative studies are rare or almost scarce in this area, suggesting the urge to fulfil this gap. The researchers can address the scarcity of qualitative studies by conducting case studies of sectors, such as banks, where property deviance is more prevalent. Participatory research is another form to explore the in-depth understanding of the phenomenon and to reflect upon it. Thus, qualitative research will contribute to the $\mathrm{OB}$ and management literature to identify the world view of the employees who get engaged in such behaviours. With this, researchers can build an informed policy recommendation through conducting participatory research.

The researchers believe that the WD is not actual and comes under social constructivist epistemology. The use of social constructivism to study the cultural prospect of the organization resulting in WD, another approach is ethnographic studies. Qualitative researchers can conduct a plethora of research in this area, considering the lack of investigation from the social constructivist lens.

\section{Framework for future research}

The literature has depicted a rich picture of WD antecedents, where the research is sparse regarding its consequential side. Mawritz et al. (2017) investigated supervisor's self-regulation impairment, while Earle et al. (2010) investigated employee turnover and strikes as a consequence of WD. Except these, the literature has not explored the research on outcomes. Considering the need to clarify the association between personality and both ID and OD (Colbert et al., 2004), the study proposes a considerable need to develop a framework for outcomes of WD.

The research further aims to provide an outline concerning the consequences of WD. Future studies can use either onedimensional or two-dimensional constructs. It is among the first few studies postulating the need to explore another side of the picture. Besides, the construct of WD can be separately analysed to dig out its association with various consequences. Examples of variables include; interpersonal facilitation, interpersonal trust, on one hand, organizational commitment, and creativity on the other. In their recent work, Mawritz et al. (2017) empirically identified subordinate's deviance as a factor behind instigating dispositional personality among leaders such as abusive supervision. The framework in figure 4 provides future directions. The framework holds the potential to underline the collective impact of WD on an interpersonal level or the organizational level.

Understanding WD and its relationship with other constructs can guide organizations and scholars in recognizing the means to reduce the psychological and financial costs of deviant behaviours (Mitchell \& Ambrose, 2007). OD can be associated with the organizational level outcomes through a moderating role of contextual variables. For instance, organizational identification, organizational support, organizational climate, the cultural difference (collectivist/individualist), and the organization's ethical environment can act as moderators between the OD and organization-level outcomes such as commitment and creativity. ID and interpersonal level outcomes such as interpersonal facilitation, interpersonal trust, and satisfaction; can be influenced through moderators. These moderators include; support from colleagues, peer feedback, cultural differences (collectivist/ individualist), task-interdependence/ autonomy, and individual ethical values.

Employees may tend to adversely impact their workplace by harming the organization (i.e., organizational deviance). The employee's behavioural outcomes are their reaction determined based on exchange relations, as suggested by the social exchange theory (SET) (Blau, 1964). The theory delineates that employees tend to reciprocate the behaviours at work with an efficient attitude and performance (Cropanzano et al., 2017). The model further portrays the mediating role of cognitive, affective state, and regulatory mechanisms (i.e., ID and OD). The likelihood to positively reciprocate on 
perceiving ID of leaders may lead to negative or positive consequences at the interpersonal and individual levels. At the interpersonal level of deviance, employees can further harm their workplace by showing a low level of interpersonal facilitation and trust. Contrarily, relational cohesion theory recommends that recurring exchanges in organizations embed their employees with their workplace that develops a sense of unity among them. Survey-based or ethnographic studies can solve these ambiguities in the future. At the organizational level, the coping mechanism mediates the choices and affects an individual's feelings. These feelings as better or worse (Folkman \& Lazarus, 1985) guides an individual to remain committed or quit the organization.

The framework suggests the several outcomes of ID and OD. The employees would either likely reciprocate through showing the destructive attitude at the interpersonal level of deviance, organizational level, or both. The research assumes that the conceptual model of the present study holds substantial exploratory power for other behavioural, psychological, and attitudinal consequences connected to WD. The model can also guide the impact of WD at a multilevel (i.e., organizational and interpersonal).

\section{CONCLUSION}

The research contributes to the existing body of knowledge in management and organizational behaviour. The research makes several contributions. First, to the researcher's knowledge, this is among the first systematic literature review deeply investigated WD typology by Robinson and Bennett (1995). Second, the literature overview has provided a comprehensive insight for the scholars to review the research conducted to date. Third, the study has offered ontological and epistemological clarity on workplace deviance. These philosophical underpinnings can extend the literature by social constructivism lens. Thus, the research aims to articulate a need to consider the social constructivist lens of WD. Hence, clarity in the ontological grounds will allow the organizations to identify why few violations result in questioning few individuals as deviant while not others. Lastly, research has explored several gaps in the literature related to methodological concerns, construct dimensionality, philosophical underpinnings, and conceptual framework. The research is a step to synthesize the prominent workplace deviance literature to envisage the future of the field.

\section{LIMITATION AND IMPLICATIONS}

Despite several notable contributions in the study, there might exist some weaknesses. The researchers have explained inclusion criteria for articles and journals in the methodology section; still, the researchers can be criticized for the subjectivity. The researchers intend to overview top-tier journals owing to their wide acceptability. This resulted in the elimination of other journals. Also, the research consists of a bibliographic review and subjective interpretation of data. Other researchers may interpret the themes differently. Additionally, the developed framework lacks insufficient proposition development, suggesting the need to propose conceptual frameworks in the future. Future researchers can also empirically test the outlined constructs from the framework to fully explore the construct. The testing based on different theories may provide implications for the managers and practitioners. The research suggests industry and sector-based research. Besides, suitable methodologies such as participatory or ethnographic studies could explore novel questions in the field. Therefore, future researchers should incorporate interviews and case studies to provide a big picture to the practitioners for resolving WD in their organizations.

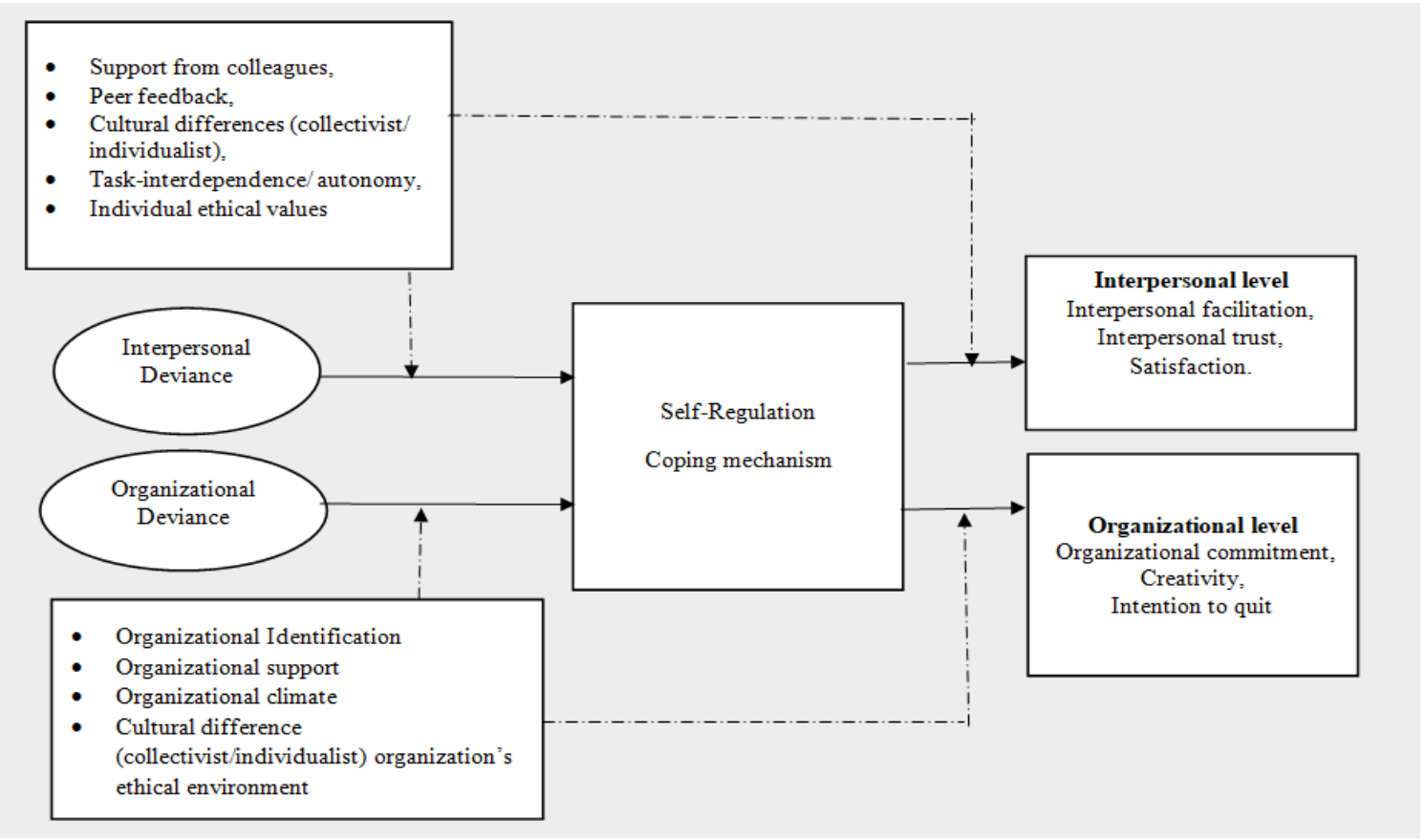

Figure 4. Framework guiding future research direction 


\section{AUTHORS CONTRIBUTION}

Mamoona Arshad: Conducted and compiled literature review, wrote the first draft.

Muhammad Abdur Rahman Malik: Supervision, feedback and comments for improving draft, helped in revisions.

\section{REFERENCES}

1. Aleksic, A., Braje, I. N., \& Jelavic, S. R. (2019). Creating sustainable work environments by developing cultures that diminish deviance. Sustainability (Switzerland), 11(24). https://doi.org/10.3390/su11247031

2. Aquino, K., Lewis, M. U., \& Bradfield, M. (1999). Justice constructs, negative affectivity, and employee deviance: A proposed model and empirical test. Journal of Organizational Behaviour, 20(7), 1073-1091.

3. Arshad, M., \& Malik, M. A. R. (2020). Workplace Deviance: A Systematic Literature Review and Future Agenda. Academy of Management Proceedings, 1-40. https://doi.org/10.5465/ambpp.2020.12473abstract

4. Bennett, R. J., \& Robinson, S. L. (2000). Development of a measure of workplace deviance. Journal of Applied Psychology, 85(3), 349-360. https://doi.org/10.1037/0021-9010.85.3.349

5. Bennett, R. J., \& Robinson, S. L. (2003). The past, present, and future of workplace deviance research. In J. Greenberg (Ed.), Organizational Behaviour. (pp. 247-281). Lawrence Erlbaum Associates Publishers. https://psycnet.apa.org/record/2003-02890-007

6. Berry, C. M., Ones, D. S., \& Sackett, P. R. (2007). Interpersonal Deviance, Organizational Deviance, and Their Common Correlates: A Review and Meta-Analysis. Journal of Applied Psychology, 92(2), 410-424. https://doi.org/10.1037/0021-9010.92.2.410

7. Blau. (1964). No Title Exchange and Power in Social Life. Willey.

8. Bouncken, R. B., Gast, J., Kraus, S., \& Bogers, M. (2015). Coopetition: a systematic review, synthesis, and future research directions. Rev Manag Sci, 9, 577-601. https://doi.org/10.1007/s11846-015-0168-6

9. Bryant, M., \& Higgins, V. (2010). Self-confessed troublemakers: An interactionist view of deviance during organizational change. Human Relations, 63(2), 249-277. https://doi.org/10.1177/0018726709338637

10. Chia, R. (2002). Time Duration and Simultaneity. Organization Studies, 23(6), 863-868. https://doi.org/10.117 7/0170840602236007

11. Colbert, A. E., Mount, M. K., Harter, J. K., Witt, L. A., \& Barrick, M. R. (2004). Interactive effects of personality and perceptions of the work situation on workplace deviance. Journal of Applied Psychology, 89(4), 599-609. https://doi.org/10.1037/0021-9010.89.4.599

12. Collins, B. J., \& Mossholder, K. W. (2017). Fairness Means More to Some Than Others: Interactional Fairness, Job Embeddedness, and Discretionary Work Behaviours. Journal of Management, 43(2), 293-318. https://doi.org/10.1177/0149206314527132

13. Cropanzano, R., Anthony, E. L., Daniels, S. R., \& Hall, A. V. (2017). Social exchange theory: A critical review with theoretical remedies. In Academy of Management Annals (Vol. 11, Issue 1, pp. 479-516). Routledge. https://doi.org/10.5465/annals.2015.0099

14. Deleuze, G. (1953). How do we recognize structuralism? Desert Islands and Other Texts, 1974, $170-192$.

15. Dennis, A., \& Martin, P. J. (2005). Symbolic interactionism and the concept of power. The British Journal of Sociology, 56(2), 191-213. https://doi.org/10.1111/J.1468-4446.2005.00055.X

16. Earle, J. S., Spicer, A., \& Peter, K. S. (2010). The normalization of deviant organizational practices: Wage arrears in Russia, 1991-98. Academy of Management Journal, 53(2), 218-237. https://doi.org/10.5465/amj. 2010.49387426

17. Ebrahimi, M., Kouchaki, M., \& Patrick, V. M. (2020). Juggling work and home selves: Low identity integration feels less authentic and increases unethicality. Organizational Behaviour and Human Decision Processes, 158, 101-111. https://doi.org/10.1016/j.obhdp.2019.02.005

18. Eissa, G., Lester, S. W., \& Gupta, R. (2020). Interpersonal deviance and abusive supervision: The mediating role of supervisor negative emotions and the moderating role of subordinate organizational citizenship behaviour. Journal of Business Ethics, 166(3), 577-594. https://doi.org/10.1007/s10551-019-04130-x

19. Ferris, D. L., Brown, D. J., \& Heller, D. (2009). Organizational support and organizational deviance: The mediating role of organization-based self-esteem. Organizational Behaviour and Human Decision Processes, 108(2), 279-286. https://doi.org/10.1016/j.obhdp.2008.09.001

20. Fiset, J., \& Bhave, D. P. (2021). Mind your language: The effects of linguistic ostracism on interpersonal work behaviours. Journal of Management, 47(2), 430-455. https://doi.org/10.1177/0149206319833445

21. Fishbein, M., \& Ajzen, I. (1977). Belief, attitude, intention, and behaviour: An introduction to theory and research.

22. Folkman, S., \& Lazarus, R. S. (1985). If It Changes It Must Be a Process: Study of Emotion and Coping During Three Stages of a College Examination. 48(1), 150-170.

23. Fox, S., \& Spector, P. E. (1999). A model of work frustration-aggression. Journal of Organizational Behaviour, 20(6), 915-931. https://doi.org/10.1002/(SICI)1099-1379(199911)20:6<915:AID-JOB918>3.0.CO;2-6

24. Galperin, B. L. (2003). Can Workplace Deviance Be Constructive? In Misbehaviour and Dysfunctional Attitudes in Organizations (pp. 154-170). Palgrave Macmillan UK. https://doi.org/10.1057/9780230288829_9 
25. Gok, K., Sumanth, J. J., Bommer, W. H., Demirtas, O., Arslan, A., Eberhard, J., Ozdemir, A. I., \& Yigit, A. (2017). You May Not Reap What You Sow: How Employees' Moral Awareness Minimizes Ethical Leadership's Positive Impact on Workplace Deviance. Journal of Business Ethics, 146(2), $257-277$. https://doi.org/10.1007/s10551-017-3655-7

26. Greenbaum, R. L., Mawritz, M. B., Bonner, J. M., Webster, B. D., \& Kim, J. (2013). Supervisor expediency to employee expediency: The moderating role of leader-member exchange and the mediating role of employee unethical tolerance. Journal of Organizational Behaviour, 39(4), 525-541. https://doi.org/10.1002/job.2258

27. Gruys, M. L., \& Sackett, P. R. (2003). Investigating the Dimensionality of Counterproductive Work Behaviour. International Journal of Selection and Assessment, 11(1), 30-42.

28. Hanisch, K. A., \& Hulin, C. L. (1991). General attitudes and organizational withdrawal: An evaluation of a causal model. Journal of Vocational Behaviour, 39(1), 110-128. https://doi.org/10.1016/0001-8791(91)90006-8

29. Hannah, S., Walumbwa, F., \& Fry, L. (2011). Leadership in action teams: Team leader and members' authenticity. Personnel Psychology, 64(3), 771-802. http://onlinelibrary.wiley.com/doi/10.1111/j.17446570.2011.01225.x/full

30. Harvey, P., Martinko, M. J., \& Borkowski, N. (2017). Justifying Deviant Behaviour: The Role of Attributions and Moral Emotions. Journal of Business Ethics, 141(4), 779-795. https://doi.org/10.1007/s10551-016-3046-5

31. Hastings, S. E., \& Finegan, J. E. (2010). The Role of Ethical Ideology in Reactions to Injustice. Journal of Business Ethics, 100(4), 689-703. https://doi.org/10.1007/S10551-010-0704-X

32. Hobfoll, S. E., Halbesleben, J., Neveu, J. P., \& Westman, M. (2018). Conservation of resources in the organizational context: The reality of resources and their consequences. Annual Review of Organizational Psychology and Organizational Behaviour, 5, 103-128. https://doi.org/10.1146/annurev-orgpsych-032117104640

33. Hollinger, R. C. (1986). Acts against the workplace: Social bonding and employee deviance. Deviant Behaviour, 7(1), 53-75. https://doi.org/10.1080/01639625.1986.9967695

34. Hollinger, R. C., \& Clark, J. P. (1982). Formal and informal social controls of employee deviance. Sociological Quarterly, 23(3), 333-343.

35. Huang, G. hua, Wellman, N., Ashford, S. J., Lee, C., \& Wang, L. (2017). Deviance and exit: The organizational costs of job insecurity and moral disengagement. Journal of Applied Psychology, 102(1), 26-42. https://doi.org/10.1037/APL0000158

36. Jahanzeb, S., \& Fatima, T. (2018). How Workplace Ostracism Influences Interpersonal Deviance: The Mediating Role of Defensive Silence and Emotional Exhaustion. Journal of Business and Psychology, 33(6), 779-791. https://doi.org/10.1007/s10869-017-9525-6

37. Kluemper, D. H., DeGroot, T., \& Choi, S. (2011). Emotion management ability: Predicting task performance, citizenship, and deviance. Journal of Management, 39(4), 878-905. https://doi.org/10.1177/0149206311407326

38. Kluemper, D. H., Mossholder, K. W., Ispas, D., Bing, M. N., Iliescu, D., \& Ilie, A. (2019). When Core SelfEvaluations Influence Employees' Deviant Reactions to Abusive Supervision: The Moderating Role of Cognitive Ability. Journal of Business Ethics, 159(2), 435-453. https://doi.org/10.1007/s10551-018-3800-y

39. Mackey, J. D., McAllister, C. P., Ellen, B. P., \& Carson, J. E. (2019). A Meta-Analysis of Interpersonal and Organizational Workplace Deviance Research. Journal of Management, 1-26. https://doi.org/10.1177/ 0149206319862612

40. Malik, P., \& Lenka, U. (2018). Integrating antecedents of workplace deviance: utilizing AHP approach. Journal of Indian Business Research, 10(1), 101-122. https://doi.org/10.1108/JIBR-09-2017-0148

41. Malhotra, M. K., \& Grover, V. (1998). An assessment of survey research in POM: from constructs to theory. Journal of Operations Management, 16(4), 407-425. https://doi.org/10.1016/S0272-6963(98)00021-7

42. Mangione, T. W., \& Quinn, R. P. (1975). Job satisfaction, counterproductive behaviour, and drug use at work. Journal of Applied Psychology, 60(1), 114-116. https://doi.org/10.1037/h0076355

43. Marcus, B., Taylor, O. A., Hastings, S. E., Sturm, A., \& Weigelt, O. (2016). The structure of counterproductive work behaviour. Journal of Management, 42(1), 203-233. https://doi.org/10.1177/0149206313503019

44. Mawritz, M. B., Greenbaum, R. L., Butts, M. M., \& Graham, K. A. (2017). I just can’t control myself: A selfregulation perspective on the abuse of deviant employees. Academy of Management Journal, 60(4), 1482-1503. https://doi.org/10.5465/amj.2014.0409

45. Mayer, D. M., Kuenzi, M., Greenbaum, R., Bardes, M., \& Salvador, R. (Bombie). (2009). How low does ethical leadership flow? Test of a trickle-down model. Organizational Behaviour and Human Decision Processes, 108(1), 1-13. https://doi.org/10.1016/j.obhdp.2008.04.002

46. Mayer, D. M., Thau, S., Workman, K. M., Dijke, M. Van, \& Cremer, D. De. (2012). Leader mistreatment, employee hostility, and deviant behaviours: Integrating self-uncertainty and thwarted needs perspectives on deviance. Organizational Behaviour and Human Decision Processes, 117(1), 24-40. https://doi.org/10. 1016/j.obhdp.2011.07.003

47. Mitchell, M. S., \& Ambrose, M. L. (2007). Abusive supervision and workplace deviance and the moderating effects of negative reciprocity beliefs. Journal of Applied Psychology, 92(4), 1159-1168. https://doi.org/10 .1037/0021-9010.92.4.1159 
48. Mo, S., \& Shi, J. (2017). Linking ethical leadership to employee burnout, workplace deviance and performance: Testing the mediating roles of trust in leader and surface acting. Journal of Business Ethics, 144(2), $293-303$. https://doi.org/10.1007/s10551-015-2821-z

49. Mongeon, P., \& Adèle Paul-Hus. (2016). The journal coverage of Web of Science and Scopus: a comparative analysis. Scientometrics, 106, 213-228. https://doi.org/10.1007/s11192-015-1765-5

50. Mooney, L. A., Knox, D., \& Schacht, C. (2007). The Three Main Sociological Perspectives. In Understanding Social Problems (5th Edition). https://www.amazon.com/Understanding-Problems-Schacht-CarolinePaperback/dp/B010WI2QAQ

51. Narayanan, K., \& Murphy, S. E. (2017). Conceptual Framework on Workplace Deviance Behaviour: A Review. Journal of Human Values, 23(3), 218-233. https://doi.org/10.1177/0971685817713284

52. Neves, P., \& Champion, S. (2015). Core self-evaluations and workplace deviance: The role of resources and self-regulation. European Management Journal, 33(5), 381-391. https://doi.org/10.1016/j.emj.2015.06.001

53. Ogunfowora, B., Weinhardt, J. M., \& Hwang, C. C. (2021). Abusive supervision differentiation and employee outcomes: the roles of envy, resentment, and insecure group attachment. Journal of Management, 47(3), 623653. https://doi.org/10.1177/0149206319862024

54. Peng, Y. C., Chen, L. J., Chang, C. C., \& Zhuang, W. L. (2016). Workplace bullying and workplace deviance: The mediating effect of emotional exhaustion and the moderating effect of core self-evaluations. Employee Relations, 38(5), 755-769. https://doi.org/10.1108/ER-01-2016-0014

55. Podsakoff, P. M., MacKenzie, S. B., \& Podsakoff, N. P. (2012). Sources of method bias in social science research and recommendations on how to control it. Annual Review of Psychology, 63, 539-569. https://doi.org/10.1146/annurev-psych-120710-100452

56. Quade, M. J., Perry, S. J., \& Hunter, E. M. (2019). Boundary Conditions of Ethical Leadership: Exploring Supervisor-Induced and Job Hindrance Stress as Potential Inhibitors. Journal of Business Ethics, 158(4), 11651184. https://doi.org/10.1007/s10551-017-3771-4

57. Robinson, S. L. (2008). Dysfunctional workplace behaviour. In Barling \& C. L. Cooper (Eds.), Organizational Behavior: Vol. Vol. 1 (pp. 141-159). Wiltshire: SAGE Publications.

58. Robinson, S. L., \& Bennett, R. J. (1995). A typology of deviant workplace behaviours: A multidimensional scaling study. Academy of Management Journal, 38(2), 555-572. https://doi.org/10.2307/256693

59. Salajeghe, S., Sohi, Z., \& Farahbakhsh, A. (2016). Explaining the relationship between the organizational climate, meritocracy and job deviant behaviours of staff (Case study of Sharcheshmehe copper and Meiduk copper mines). International Journal of Humanities and Cultural Studies (IJHCS), 2(4), 989-1009.

60. Saussure, F. D. (1959). Course in General Linguistics.

61. Shantz, A., Alfes, K., \& Latham, G. P. (2016). The buffering effect of perceived organizational support on the relationship between work engagement and behavioural outcomes. Human Resource Management, 55(1), 2538. https://doi.org/10.1002/hrm.21653

62. Shantz, A., \& Booth, J. E. (2014). Service employees and self-verification: The roles of occupational stigma consciousness and core self-evaluations. Human Relations, 67(12), 1439-1465. https://doi.org/10.1177 /0018726713519280

63. Shoaib, S., \& Baruch, Y. (2019). Deviant behaviour in a moderated-mediation framework of incentives, organizational justice perception, and reward expectancy. Journal of Business Ethics, 157(3), 617-633. https://doi.org/10.1007/s10551-017-3651-y

64. Shoss, M. K., Jundt, D. K., Kobler, A., \& Reynolds, C. (2016). Doing bad to feel better? An investigation of within- and between-person perceptions of counterproductive work behaviour as a coping tactic. Journal of Business Ethics, 137(3), 571-587. https://doi.org/10.1007/s10551-015-2573-9

65. Song, L., Wang, Y., \& Zhao, Y. (2020). How employee authenticity shapes work attitudes and behaviours: The mediating role of psychological capital and the moderating role of leader authenticity. Journal of Business and Psychology, 1-12. https://doi.org/10.1007/s10869-020-09725-0

66. Spector, P. E., Fox, S., Penney, L. M., Bruursema, K., Goh, A., Kessler, S., \& Spector, P. E. (2006). The dimensionality of counterproductivity: Are all counterproductive behaviours created equal? Journal of Vocational Behaviour, 68, 446-460. https://doi.org/10.1016/j.jvb.2005.10.005

67. Stewart, S. M., Bing, M. N., Davison, H. K., Woehr, D. J., \& McIntyre, M. D. (2009). In the eyes of the beholder: A non-self-report measure of workplace deviance. Journal of Applied Psychology, 94(1), $207-215$. https://doi.org/10.1037/a0012605

68. Thornton, M. A., \& Rupp, D. E. (2016). The joint effects of justice climate, group moral identity, and corporate social responsibility on the prosocial and deviant behaviours of groups. Journal of Business Ethics, 137(4), 677-697. https://doi.org/10.1007/s10551-015-2748-4

69. Vogel, R. M., \& Mitchell, M. S. (2017). The motivational effects of diminished self-esteem for employees who experience abusive supervision. Journal of Management, 43(7), 2218-2251. https://doi.org/10.117 7/0149206314566462

70. Wilson, R. A., Perry, S. J., Witt, L. A., \& Griffeth, R. W. (2015). The exhausted short-timer: Leveraging autonomy to engage in production deviance. Human Relations, 68(11), 1693-1711. https://doi.org/10.11 77/0018726714565703 
71. Yam, K. C., Klotz, A. C., He, W., \& Reynolds, S. J. (2017). From good soldiers to psychologically entitled: Examining when and why citizenship behaviour leads to deviance. Academy of Management Journal, 60(1), 373-396. https://doi.org/10.5465/amj.2014.0234

72. Zagenczyk, T. J., Restubog, S. L. D., Kiewitz, C., Kiazad, K., \& Tang, R. L. (2014). Psychological contracts as a mediator between Machiavellianism and employee citizenship and deviant behaviours. Journal of Management, 40(4), 1098-1122. https://doi.org/10.1177/0149206311415420

73. Zhang, C., Mayer, D. M., \& Hwang, E. (2017). More is less: Learning but not relaxing buffers deviance under job stressors. Journal of Applied Psychology, 103(2), 123-136. https://doi.org/10.1037/apl0000264 